\title{
Transportation Demand Management and a Flexible Education System (Mobility vs. Access)
}

\author{
Akin Seber ${ }^{1}$ \\ ${ }^{1}$ Department of Financial Economics and Faculty of Commercial Sciences, Yeditepe University, Istanbul, \\ Turkey \\ Correspondence: Akin Seber, Faculty of Commercial Sciences, Yeditepe University, Inonu Mah., Kayisdagi \\ Cad., 26 Agustos Yerlesimi, Atasehir 34755, Istanbul, Turkey. E-mail: aseber@yeditepe.edu.tr
}

Received: June 9, 2014

Accepted: July 11, 2014

Online Published: September 25, 2014

doi:10.5539/ijef.v6n10p168

URL: http://dx.doi.org/10.5539/ijef.v6n10p168

\begin{abstract}
In this paper, we analyze how Information Technology-IT can be used as a substitute for Transportation-TT in education system. We propose framework of a Flexible Education System-FES, which enables different degrees of substitution of IT for TT based on preferences. We analyze the Costs and Benefits of each system and leave the decision to the policy implementers to decide on the most appropriate alternative. The analysis is based on the difference between Mobility and Access, and has important implications for Environmental Externalities and Community Livability. The results of the paper also have implications for other types of work to the degree of substitutability of IT for TT for commuting.
\end{abstract}

Keywords: information technology, education system, cost-benefit analysis, mobility, access, transportation demand management

\section{Introduction}

In this paper, we want to analyze how Information Technology-IT may be used as a substitute for Transportation-TT as a Transport Demand Management-TDM policy in education system. Furthermore, the education system serves as an example such that the same kind of substitution may also take place in other convenient work types. These work types may be management, design, architectural work, sales, marketing, financial services, and secretarial, administrative work among others (Button et al., 2006). Actually, by its nature, the type of interaction between IT and TT may also consist of enhancement as well as synergy with complex social, economic and technological forces besides from being substitutes. For the purpose of this paper, however, we concentrate on the substitute dimension since we want to focus on the positive economic, social and environmental impacts of using IT instead of TT.

For the purposes of the paper, Transportation Demand Management-TDM (also called Mobility Management) is an area where different policies are recommended for the purpose of reducing transportation. As the term TDM suggests, the idea is not to take transportation demand as a fixed quantity, but consider it as a variable depending on the activity that transportation serves. Actually, transportation is considered as a derived demand, a demand stemming from the demand for another activity. This derived demand nature can both be direct (as in commuting, shopping or recreation), or indirect (like in warehousing or oil production). For our purposes, the demand in the education system is "Learning", and there is a derived demand for transportation in order to reach this education goal.

In reality, TDM is a much broader concept, within which IT substitution for TT is only one of the policy tools that can be implemented for reaching various transportation objectives. In a more general sense, TDM refers to various strategies implemented to increase transport system efficiency and reach specific planning objectives by means of changing travel behavior of people (how, when and where people travel). The consequences of different TDM policies are reported as the following (TDM Encyclopedia):

1) "Congetion reduction: Reduces traffic congestion delays and associated costs;

2) Road and parking savings: Reduces road and parking facility costs;

3) Consumer savings: Helps consumers save money by reducing their need to own and operate motor vehicles; 
4) Transport choice: Improved travel options, particularly for non-drivers;

5) Environmental protection: Reduced air, noise and water pollution, wildlife crashes and other types of environmental damages;

6) Efficient land use: Supports strategic land use planning objectives, such as reduced sprawl, when redevelopment and reduced habitat fragmentation;

7) Community livability: Improved local environmental quality and community cohesion;

8) Economic development: Supports a community's economic objectives, such as increased productivity, employment, wealth, property values and tax revenues;

9) Physical fitness and health: Improved public fitness and health due to more physical activity, usually through increased daily walking and cycling".

As far as "IT at Home" as a substitute for "TT at Work" policy is concerned, two important terms are Mobility and Access. Transportation is related with mobility in such a way that with the demand for education, there is a need for people to be mobile, creating a demand for transportation, motorization and energy (petroleum). With the mobility of people, however, there are also internal costs (users), external costs (society), and environmental impacts. We want to stress the distinction between mobility and accessibility. It is physical movement of people or goods in mobility that is important, whereas it is the ease of reaching desired goods, services, activities in accessibility. Therefore, it's no wonder that the meaning of transportation is different in a traffic, mobility and access sense such that while traffic focuses on vehicle travel, mobility focuses on person and goods movement and accessibility refers to ability to obtain goods, services and activities, respectively. For the purposes of this paper, IT use may be considered as an accessibility strategy, while vehicle transportation is traffic or mobility strategy. The basic intuition is this: If the same task (for all practical purposes) can be achieved (accessibility) without people moving around so much (mobility-with associated private, social costs and externalities), it should be preferable to the others. Actually, there is no need for referring to economic terms such as technical efficiency (production with least inputs) or cost efficiency (production with least costs) to agree on this, because simple common sense would also be enough for this choice (assuming that people are sane in the sense that they are not masochistic or have plenty of time and resources they want to waste).

Considering the motivation for this study, we might mention our observations at the university, where the students use public transportation, the service buses or their own cars for commuting purposes. And like many other cities in the world, traffic congestion is one of the major problems causing them to take around 1-4 hrs. in commuting to class and then back home. With the tiring effects of so much transportation, it is not uncommon for us to hear that they want to leave early in evening classes, for example, not to remain to the rush hour, where the time of travel unnecessarily lengthens. With the "stress factor" of traffic including "noise", "time" and "dealing with other drivers/people", students sometimes "exist in class quantitatively-QN (that is signing the attendance sheet), but not qualitatively-QL (that is paying attention to what is discussed in class and learning). It may be normal in a military setting where every morning you count the number of people to see if there are any missing personnel, but it is questionable to state the same argument in an education setting. This is simply because, the important thing appears to be "Learning and Applying Knowledge-(LAK)" rather than any other criteria (Seber, 2011b) in education.

Referring to the their developmental stage, transportation problem is only among the many problems that students have to deal with including, for example, "daily chaotic news environment", their "economic problems including career concerns" and their "developmental problems" including their relationships with their parents and their friends. This situation causes losses in productive efficiency, and any approach that decreases the personal costs of transportation will increase their ability to reach their potential for learning, assuming a "Potential Oriented-PO" performance evaluation system for their development (Seber, 2011a, b). Thinking in economic terms, since the current condition is within the production possibility frontier-PPF, looking from their potential perspective, any improving policy implementation would have no opportunity cost.

It is not a new idea that IT can be implemented as a substitute for TT in various work settings, including research and training-education (since they are considered as areas most suitable for the policy implementation). The contribution of the paper is to recommend a framework of how it can be implemented, and if implemented, try to make a detailed cost-benefit analysis of the consequences including economic, social, environmental, land use as well as productive efficiency concerns for individuals. Furthermore, the implementation of the recommended policy in the education system may serve as an example for other types of work suitable for IT substitution for TT, with increasing POSITIVE effects on societies in economic, social and environmental dimensions. In the 
following, we first describe the policy recommendation in section 2, carrying a cost-benefit analysis as well; and leave it to section 3 for analyzing the secondary effects of these policies, with possible application of the model to other work areas; finally section 4 summarizes our results.

In the study, we use several studies done in this area as given in the reference section, which are by no means comprehensive, and we don't intend it to be so (maybe not so necessary). The interested readers may carry their research further by looking at the references in them. These references, however, are sufficient for the purposes of setting out the framework for our model. Furthermore, the analysis in this paper is also based on our previous papers in the area of performance measures and organizational structure to be used in education (Seber 2011a, b, c).

\section{Method}

\subsection{Policy Recommendation}

The implementation of IT (a personal computer with internet connection), can be used as a substitute for TT in "Varying Degrees-VD". The term VD is important here, because users of this policy have "the right but not the obligation to exercise", like in an option contract rather than a forward contract, making a financial analogy. IT has already proved itself as a complementary tool in education, by aiding communication with students and transfer of documents during classes. With the VD policy, the IT technology may be used in a flexible manner depending on preferences, as a substitute to TT policy of in class education. The policy tool for this can be summarized with the following linear equation:

$$
X=\alpha 1_{I T}+(X-\alpha) 1_{T T}
$$

In the equation, $1_{\mathrm{IT}}$, and $1_{\mathrm{TT}}$ may be considered as "time" spent in education with IT at home education and TT in class education; $\alpha$ is total days of education with IT. We propose a hybrid policy structure with weekly and semester programs. In a weekly program, $\alpha \in[0,5]$, and $X=5$; and in a semester program $\alpha \in[0,14], X=$ 14;.In a weekly program, the students may have in class education after $\alpha$ weeks of working in an IT environment and passing a threshold level of knowledge. In the hybrid framework, it is also possible to combine the weekly and semester programs by arranging in class education in certain days of the week in varying proportions.

Network analysis is suitable for the purpose of modeling here. Based on the network of students connected to the instructor via a PC with internet connection, for example, connectivity or accessibility of each student may be measured. Here, connectivity index of the instructor would be the highest, while each student may also have connections to other students that they are friends with. We also want to introduce a Needed Travel Distance$d_{i j}$ measure for determining whether a student will continue with second stage of in class education after $\alpha$-week of at home education. NTD in a network structure is determined by the following equation:

$$
N T D_{i j}=d_{i j}=\left(\hat{A}_{i j}-A_{i j}\right)
$$

In the equation, $d_{i j}$ is the distance student $i$ should travel in a knowledge sense in subject $\mathrm{j}$; $\hat{\mathrm{A}}_{i j}$ is the threshold level of knowledge of student $\mathrm{i}$ in subject $\mathrm{j} ; A_{i j}$ is the current level of knowledge of student $\mathrm{i}$ in subject $\mathrm{j}$. $\hat{\mathrm{A}}$ is set at the beginning of classes by the instructors based on each student's previous studies, ability and interest; the total number of students in class is $n$, number of subjects $m$, and the distance between the student $\mathbf{i}$ in subject $\mathbf{j}$ and knowledge amount $\hat{\mathrm{A}}_{i j}$ (distance that is not in a transportation framework as between the student and the school, but in a knowledge framework) is $\boldsymbol{d}_{\boldsymbol{i} \boldsymbol{j}}$. This is because, what is important for educational purposes is "learning and applying knowledge-LAK" rather than transporting around, access rather than mobility, cost efficiency rather than production with negative externalities and QL rather than QN.

The performance of the education system may also be measured by the following measure (among other possible measures, for example):

$$
A D T_{I T}=\sum_{i=1}^{n}\left[\left(d_{i j}\right)_{t=0}-\left(d_{i j}\right)_{t=1}\right] / n
$$

In the equation, $\mathrm{ADT}_{\mathrm{IT}}$ would stand for "average distance travelled-ADT" of students in the "IT at Home" part of the education. If we replace IT with IC (for "TT in Class" part of the education), $\mathrm{n}$ with $\mathrm{k}$ (the students with negative or zero NTD at the end of period 1 ), and $t=0,1$ with $t=1,2$, respectively (indicating the second part of the education), we would measure the $\mathrm{ADT}_{\mathrm{IC}}$ of students in the "TT in Class" part of the education system (IC standing for "TT in Class"). A larger $\mathrm{ADT}_{\mathrm{IT}}$ or $\mathrm{ADT}_{\mathrm{IC}}$ would indicate a better performance for the relevant part of the education system. This performance measure is also in congruence with "learning and applying knowledge-LAK" measure proposed in our previous paper (Seber, 2011b). 
Here, the attributes of each student and the geometric distance are different in an IT rather than TT framework. In a TT framework, the attribute may be considered as the population of a location and geometric distance is the distance from the student's home to the school, for example. On the other hand, in an IT framework attribute represents the student's endowment of previous knowledge as well as his potential and interest for learning the subject material, which may be measured by specific tests before the in class part of the education starts. Furthermore, the distance would no longer be the physical distance, but the distance to the specified objectives set out at the beginning of the course, for example, distance to knowledge or distance to specific attitudes for learning materials. In a semester program, the NTD of each student may be measured at a Midterm Exam, and only those students who have reached or passed a threshold level, that is with a negative or zero NTD level may be allowed to continue in class lectures for the second half of the course. This will increase the efficiency of the lectures for the simple fact that only those students who are interested and established their ability for learning the subject will attend the classes. There will be less distraction from other uninterested, unable students. And the motivation level of the Instructor will also be high, for he/she will no longer spend most of his time trying to tell the students to listen or be quite in class, but instead focus on explaining subjects to able- interested students.

This method also enables categorizing students for example as A, B, C level students. Those who showed their ability-interest at early time will be considered as A students, while those who never were able to pass the threshold level may be considered as $\mathrm{C}$ level students. Therefore, each student may be graded within their ability-interest category. Transportation will be less of a distortionary factor here, since the students will have established their ability-interest in an IT environment, and stress or distractions will be less of a concern. Furthermore, the categorization of students may also solve the economic concerns of the Education Organization enabling both QN and QL students to attend, maybe not all of them in a TT in class part of the education, but at least the IT at home part. With this categorization, it will be beneficial for the students of high ability-interest for the simple fact that it will be possible to teach them at a more advanced level. Actually, this methodology means moving from a "pooling equilibrium-PE" in a situation of "adverse selection" (ex-ante incomplete information problem) in an "information economics setting" to "separating equilibrium-SE". Also, since the students can not attend classes before they show that their ability-interest level is at appropriate levels, the new framework also solves the "moral hazard" problem, since low ability-interest students no longer produce externalities on high ability-interest students after being accepted to attend the class (ex-post incomplete information problem). Attending classes will be a privilege to be obtained by the proper conduct of the students, rather than a right, where they can do anything they want once they get in.

One of the important factors here is whether the students will actually work when there is no close monitoring of their actions as in TT in class, or whether they will use other people for doing their HWs, for example, in an IT at home education system. Another problem is whether other vehicles will fill in the gap of decreased transportation of students by increasing their transportation levels, when one of the intentions for the policy implementation was to decrease the needed transportation level in a TDM perspective with decreased personal, social and environmental costs. Similarly, another problem is whether the students will use their vehicles for sightseeing purposes when they do not commute to school. For example, according to a survey recently conducted in California, almost $50 \%$ of a sample of 1,300 workers preferred a commute of 20 minutes or more during the day, indicating a tendency for using cars during the day (Button et al., 2006).

We think that some of these problems are related with the "Level of Trust-LT" between the students and the education system. There might be other less costly mechanisms that may establish the high LT, even if making them transport to classes every day may also be one of them. For example, letting the students who attend the class sign a paper at the beginning of the semester stating that all the work they do at home will be their own work and they will spend specific amounts of time for the class, leaves the control mechanism to the "Honor of Students" based on their promise, which is an internal control mechanism rather than an external one. The violator of the promise will also be the loser, because the student actually will have deceived himself. Furthermore, the measurement system can also be used with several measures to reveal how much the student has worked for the class with IT at home. Even if a student working part-time while attending classes may not be a problem, for he will also be contributing to his family expenses being productive and decreasing a possible financial pressure on him by his parents. The other problems also are solvable by an increased environmental consciousness of all citizens and also by the cost-efficiency of the IT at home as a substitute for TT in class education. Certain rules might also be implemented to the degree of importance given to environmental concerns.

\subsection{Cost Benefit Analysis}

At this point, we can make a comparison of "IT at Home" and "TT in Class" education systems in a Cost-Benefit 
framework. According to the analysis carried out in (Button et al., 2006), the following are the possible benefits and costs of using "IT at Home" as a substitute for "TT at Work" for any type of work (not necessarily in an education setting). According to this analysis some of the benefits are:

- Reductions in office space requirements-including lighting, space, and furniture;

- Higher staff productivity through fewer interruptions;

- Higher efficiency (for example less transportation time and payments);

- Less dependance on climate conditions;

- Greater flexibility in working hours;

- Greater flexibility in life-style;

- Higher productivity through fewer interruptions;

- Achieve more life goals in a day;

Costs:

- Requires self-discipline;

- Possible lower productivity due to home-based distractions, lack of direct supervision;

- Possible less effective communication between personal due to lack of proximity;

- Less opportunity for cross-fertilization resulting from social /professional face-to-face interactions;

- Provision and maintenance of equipment;

- Increased information security problems;

- Requires dedicated space in the home;

- Internal household conflicts.

We will define the items counted above (and any possible additions not referred to in the list) with variables $\mathrm{TB}_{\mathrm{IT}}$ and $\mathrm{TC}_{\mathrm{IT}}$, representing total benefit and total cost of "IT at Home" type of work. The full cost-benefit analysis will also have to include the costs of transportation, $\mathrm{TC}_{\mathrm{TT}}$, and we think that it is possible to consider $\mathrm{TB}_{\mathrm{TT}}$ function as negligible, assuming of course that, there is no need to create jobs just for the sake of creating employment areas for people. This may of course need some structural change support of governments, for everyone to be better off in the long-run, thereby "Structural Change Cost-SCC $\mathrm{IT}_{\mathrm{ITTT}}$ ". With the above definitions, we can now represent the necessary "Net Benefit-NB" function for "IT at Home" as a substitute for "TT at Work" policy:

$$
N B_{I T-T T}=\left(T B_{I T}-T C_{I T}\right)+\left(T C_{T T}-S C C_{I T-T T}\right)
$$

Before making any detailed analysis of the $\mathrm{TC}_{\mathrm{TT}}$ function, we can state that $\left(\mathrm{TB}_{\mathrm{IT}}-\mathrm{TC}_{\mathrm{IT}}\right)$ part will be negligible compared to the $\mathrm{TC}_{\text {TT }}$ part. The only important item we have to consider will then be $\mathrm{SCC}_{\text {Iт-TT }}$ part, and the smaller it is, the more feasible the policy alternative of "IT at Home" as a substitute for "TT at Work" will be.

Therefore, it is important to elaborate more on this structural change component at this point. As we stated, there will be some people who may loose their jobs as a result of the policy change, with negative economic consequences (but only in the short-run). To examine the policy analysis in the traditional framework of "Pareto Efficiency-PE", it may not be efficient since it is not possible to make at least one person better off without making anyone worse off (that is in the short run), with the implementation of policy change of "IT at Home" as a substitute for "TT at Work". However, with the "Minimum Environmental Costs-MEC" success criteria for the future of the world (Seber, 2011c), and with a structural change support of all the people and governments with an increased environmental consciousness, proper implementation of the policy may be possible with decreasing amounts of transportation, the result being better not only for all present but also for future generations of people, animals and plants. This is actually achieving PE for all in the long-run.

At this point we will briefly comment on $\mathrm{TC}_{\mathrm{TT}}$ component and leave it to section 3 to elaborate more on it referring to some information about these costs. The costs of transportation may be analyzed in 3 groups of private, social and environmental costs. The classification given in (Rodrigue et al., 2006) is vehicle ownership, vehicle operating, operating schedules, travel time, internal accident, external accident, internal parking, external parking, congestion, road facilities, roadway land value, municipal services, air pollution, noise, resource consumption, land use impacts, water pollution and waste disposal. Similarly transport costs are defined as user costs (consisting of vehicle ownership, operations and maintenance), user transfers (infrastructure, accidents and safety), infrastructure costs, environmental costs, noise costs, accident and safety costs and time costs in 
(Wikipedia Encyclopedia).

All of these costs and any additions which we recommend in section 3 below may be summarized with the following transportation cost function:

$$
T C_{T T}=T C_{T T-E C}+T C_{T T-S}+T C_{T T-O}+T C_{T T-L U}+T C_{T T-E N V}
$$

Here, the terms represent total transportation costs, which are further categorized as economic, social, organizational, land-use and environmental costs (which also includes health and fitness costs), respectively, in the equation. We think the previous analysis of transportation costs is necessary but not sufficient since it is possible to look at the problem in a broader perspective of the categories defined in equation (5).

Therefore, based on a more general Cost-Benefit analysis, arguing that savings from "IT at Home" as a substitute for "TT at Work" policy for employees is only: "Office cost savings (37\%), reduced parking requirements (1\%), increased employee effectiveness (32\%), decreased sick leave (3\%), increased organizational effectiveness $(2 \%)$, decreased turnover (11\%), telecommunications replacement costs (14\%)" (TDM Encyclopedia), will not represent the whole picture, but only will be looking at the problem from the perspective of $\mathrm{TB}_{\text {IT }}$ perspective.

In the following, we want to first stress the fact that we use some information about transportation as given in (Rodrigue et al., 2006) without rewording or adding any comment to have a more general idea about different dimensions of urban transportation. In each of the categories below, we first introduce our analysis including economic, social, organizational, land use, environmental effects of transportation (as given in equation 4)), and then support our ideas by using information mentioned in (Rodrigue et al., 2006). The categories analyzed in this section are to be used in the NB function mentioned in equations (4) and (5), analyzing "IT at Home" as a substitute policy for "TT at Work" policy.

\section{Application}

In a recent study, only $10 \%$ of urban transportation is typically attributed to educational purposes (Rodrigue et al., 2006), so the policy recommendation for a FES may have minor urban transportation implications. However, there is nearly $60 \%$ work related urban transportation and the same kind of analysis may also be implemented to those work areas for significant contributions to the environmental as well as urban transportation problems. The percentages may be different depending on the city of concern, but there appears to be a large potential for applicability of "IT at Home" policies as a substitute for "TT at Work" polices with positive economic, social, organizational, land use, environmental, and health effects.

\subsection{Economic Effects}

As far as the economic effects of the policy shift is concerned, it is normal to expect a reduction in economic activities. In the short-term, any producer related with transportation may be negatively affected, including car manufacturers, oil companies or parking lot operators, for example. However, there is a possibility for everyone to win in the long-run with the proper structural change policy implementations of governments for the structural change. The GDP of countries may decline with less people transporting around, but the same production will be made with less negative external effects with increased efficiency.

Actually, it might be important to mention about 2 different GDP measures proposed by the United Nations (EDP-Eco-Domestic Product, 1993) and the World Bank (Genuine Saving, 1997) to be used in place of GDP. EDP is estimated by deducting "depreciation of produced assets" from GDP to find Net Domestic Product. Further deductions of "depletion of natural resources", and "pollution damages" yields EDP, which is considered as a truer measure of income. On the other hand, Genuine Saving is estimated by first deducting "consumption of goods and services" from GDP to find Gross Saving. Further deductions of "depreciation of produced assets" yields Net Saving and "depletion of natural resources" and "pollution damages" yields Genuine Saving, which is to measure sustainability. The use of these "greener" accounting measures would also support the "IT at Home" as a substitute for "TT at Work" policy recommended in this paper.

Among the other economic affects of the recommended policy implementation will be the effect on balance of payments-BOP of countries. Oil is a very important import or export item for many countries, and the policy implementation may have positive BOP effects in case the country is in an "oil-importer rather than oil-exporter" position. As a macroeconomics principle, a negative current account balance which is financed by capital inflows with relevant interest payments, may cause double exploitation of countries. Furthermore, to the extent that decreasing capital inflows cause a depreciation of the domestic currency, exports will be affected positively and imports negatively. In effect, this result means a substitution of domestic production and employment for foreign production and employment, depending on the price elasticity of demand for different goods and services. Therefore, the effect of the policy on trade balance is twofold: The first one through the reduction in oil imports; 
the second one through the price effect of changing exchange rates.

On the other hand, oil companies or capital owners may not like this policy to be implemented (in the short-run), but if a country or a person is not exploited for that matter, it means a more healthy and fair economic environment. Actually, the policy implementation may also contribute to world peace, because as people are fighting each other to have control of the natural resources including oil. Less dependence on oil would also mean fewer wars, and also less instability both in a political sense and economic sense. In an economic sense, the countries will be less affected by fluctuations imposed by changes in oil prices, even though those benefiting from instability and volatility may lose (at least in the short-term).

The following are some facts which may help to estimate the magnitude of the economic impacts of the policy change as mentioned in (Rodrigue et al., 2006):

- "Energy consumption: Transportation activities are large consumers of energy, especially oil. About $60 \%$ of all the global oil consumption is attributed to transport activities, the other major petroleum using activities being Industrial, Residential and Commercial, and Electric Utilities. The growing level of global motorization is a core component behind this relative growth. Transport typically accounts for about $25 \%$ of all the energy consumption of an economy. Furthermore, road transportation is the most important mode in transportation.

- Petroleum production: Global world oil production is estimated to be at its maximum level in around 2010, and most of the remaining oil is expected to extracted by 2060 .

- Petroleum consumption: Road transportation is the largest fuel market accounting for $65 \%$ of all the fuel consumed by transportation. Even the marine and aviation fuel markets are comparatively smaller, their importance in supporting global trade should not be underestimated. While there are many alternatives for road transportation (rail, public transit, cycling), there are very few, if any, for long distance air and maritime transportation. Additionally, each transport sector tends to use a specific fuel quality, which is linked to its performance, as well as level of dependency.

- Equality: Car ownership can be a factor behind mobility gaps. An individual having access to a car has a more significant commuting range than an individual without a car. Poverty, handicaps, age and gender are all factors which influence the variability of mobility gaps. Therefore, people with low incomes make less trips, which incidentally restrict their access to jobs and other services, for example. Therefore, having access as the determining criteria rather than mobility have equality-improving characteristics for the society.

- Transport time: Among the different dimensions of time effect are punctuality, frequency, timing as well as transport time".

\subsection{Social Effects}

It has been suggested by Fukuyama (Fukuyama, 1996) that social interactions at workplaces are an important element of fostering a sense of community over individualism since "Work and money are much more important as sources of identity, status and dignity ... this kind of recognition cannot be achieved by individuals; it can only come about in a social context". This assumption is considered as a negative affect of IT on social interactions. However as we all know, not all interactions at work are positive relationships and there are also negative interactions, an example being "mobbing", and we think the final effect will be unclear depending upon the person and organization. Furthermore, the social dimension may move from the work place where it may actually be less important (with the task being the primary concern) to home community (where it is commonly criticized that people rarely know and interact with their neighbors or relatives due to "lack of time or being tired"). So, the social interaction dimension may not necessarily disappear, but it may actually move from a possibly less important or negative one to more important and positive one, strengthening social interactions and enhancing community building.

According to some psychologists, the interpersonal attraction dimension of social influence consists of task attraction, physical attraction and social attraction. Therefore, it may be more advantageous for employers to use telecommunications to emphasize content and minimize social influences. In this respect, telecommunications may actually help reducing socio-emotional communication and increase task orientation that can enhance group work and efficiency.

The possible analysis of "agglomeration economies" and "crowding-out effects" may be important here (Head, 2007). "Agglomeration economies" or "cluster advantages" may be described as how groups of related firms often perform better (higher productivity, more competitive products) when they choose geographically proximate locations. Crowding-out effects, however, refer to possible negative effects, for example when a 
company faces a nearby competitor, causing the company to charge a lower price and surrender market share. In a social context, IT may actually serve education purposes better when considering both agglomeration and crowding-out effects. This again is based on the fact that we observe the boredom and fatigue the students face with so much travelling around with its negative effects. It is not uncommon for us to observe student wishes of getting out of the university as soon as possible, as if learning which will be beneficial throughout their life is something to be avoided. Actually, what they may be trying to avoid is not "Learning" but "Unnecessary Costs" imposed on them by the education system making it more difficult for them to reach their goal, with a lot of transporting around in the city. "IT at Home" as a substitute for "TT in Class" policy offers an alternative for students which increases efficiency of learning as well of reducing the costs.

\subsection{Organizational Effects}

There may also be changes in organizational structure as a result of changes in the nature of work through time. In a historical perspective, the economic structure has changed from an agriculture, to heavy industry manufacturing, to an information/knowledge era. Accordingly, there was also a change from "Traditional-T" type of work relationship to more "Individualist, Boundaryless-B" type. The following analysis is based on (Button et al., 2006) classifies the difference between these two types of organizational structures:

- "Employment relationship: Job security for loyalty in $\mathrm{T}$ versus employability for performance and flexibility in B;

- Boundaries (Employers): 1 or 2 firms in T versus multiple firms in B;

- Skills: Firm specific in T versus transferable in B;

- Success measured by: Pay, promotion and status in T versus psychologically meaningful work in B;

- Responsibility for career: Organization in T versus individual in B;

- Training: Formal program in T versus on-the job for B;

- Milestones: Age-related in T versus learning-related in B".

According to this classification, the locus of control for work has shifted from the organization to the individual. The autonomy and responsibility of employees increase with telecommunications; also having positive effects on work-family balance, job satisfaction and reduced stress, worker morale, productivity and commitment by means of influencing the nature of work.

Actually, it appears that using "IT at Home" in place of "TT at Work" policy is a switch from a more "Centralized-C organization structure to a more "Decentralized-D" organization structure. Whereas the C structure is based on "Command-Control", the D structure is more based on "Trust-Empowerment". Actually, the degree of centralization or decentralization may change according to the level of the need to control versus trust. Furthermore, any policy implementation that may increase the level of trust will actually encourage moving from $\mathrm{C}$ to D organizational structure.

The following is actually a different analysis of the current change in organizational structure as given in Rodrigue et al., 2006):

- "Organizational Structure: Among the changes in corporate structure brought about by telecommunications is a change from hierarchical organizational structure to network organizational structure. In a hierarchical organization, the decision-making processes are compartmentalized. Decisions and information move vertically between levels of the structure. For a small to medium-sized corporation, this structure is usually contained within the same building, over several floors when required. Managers usually have direct physical contact with the employees under their supervision. However, in a network organizational structure, the cohesion is supported by a wider array of telecommunication services. Proximity and direct contacts, at least for mundane tasks, are no longer a priority. As a result, some tasks can be relocated elsewhere, either in lower cost offices or at home".

\subsection{Land Use Effects}

In the case of automobile dependency for example, there will be a lot of land allocated for infrastructure and parking purposes. Furthermore, it affects the sprawl of the city as well as decreasing recreational areas within the city with negative health effects. In many large cities, when you look out of the window, you only see large buildings, roads and cars (either going and making noise or parked and occupying valuable space), which are not healthy. Actually, doctors state that the longer distance you can see when you look out of the window and the more natural the environment with trees, rivers, birds etc., the healthier it is. Therefore, by means of making 
transportation the number 1 priority in cities, the citizens actually disregard their health concerns by means of preferring to live in an unnatural environment. There is an important concern here, however, that a more healthy living environment based less on automobile transportation would also mean a redesign of urban structure. This may not be in the best interest of some parties like municipalities or construction companies (in the short-term), but will be beneficial for all (in the long-term), with possible support of the governments for structural change.

We can also refer to the following information provided in (Rodrigue et al., 2006) for land use analysis:

- “Traffic Congestion: Typically, two peak hours in urban transportation are around 8am. and 5pm. corresponding to home-to-work trips. Shopping trips mostly occur during the afternoon, while social/recreational trips mainly occur in the evening. The unequal distribution of movements is often creating congestion at peak hours. Among the policy implementation to prevent peak hour congestion management are flexible work schedule, land use modifications, and transport constraining.

- Considering the situation in the U.S., while in the early $1980 \mathrm{~s}$, the great majority (65\%) of the urban circulation in major American cities occurred in an uncongested setting, by the early $21^{\text {st }}$ century the situation degraded considerably so that about $66 \%$ of the urban circulation occurs under congestion and more than half of it under heavily congested situations.

- Urban Structure: Different Urban Spatial Structures in terms of form, pattern and interaction have different implications for transportation. An urban structure with grid-like spatial form with limited centrality, a highly fragmented and dispersed spatial form, and random pattern and low intensity spatial interactions would imply more environmental impacts attributed to land use. This is because of transportation demand such a spatial structure creates.

- Urban Density: In all of the world's largest metropolitan areas, density, measured in people per square $\mathrm{km}$. has substantially declined in recent decades. This is jointly the outcome of the expansion of respective areas as well as suburbanization. There is an intricate relationship between urban density and energy (fuel) consumption. North American Cities are among the most energy intensive while Asian Cities are highly energy friendly.

- Transportation Movement: Most of the transportation that takes place in urban areas are between suburban area and central city, within the suburban area, and within the central city.

- Location Choice: Locational change is a process according to which the number, capacity and nature and the location of production is modified with the purpose of making it more efficient (cost effective) and to better service the needs of the market. Locational choice may involve intensification, specialization, concentration and rationalization- relocation. Basic location strategies are based on the principle of revenue maximization and cost minimization.

- Land Use: According to a study done in 1999 for determining the land area consumed by the car in selected countries, different nations establish different patterns. Although Japan is the country that has the largest share of its territory devoted to road transportation (3.5\%), it is Canada that allocates the largest amount of space per capita to the automobile (734 square meters per person), followed by the United States (573). While the percentage of total land area used by the car is an indication of density and economic intensity, area per capita figures are an indication of car dependency. In the U.S., about 155,000 square $\mathrm{km}$. are reserved for car use, which equals to $10 \%$ of all the available land. Even if total area values are relatively small, road and parking facilities are dominantly concentrated in urban areas.

- Public Transit: Among the challenges of urban transit are decentralization, connectivity and fixity. Decentralization and suburbanization have created an urban space of lower density that can not be efficiently serviced by mass transit systems outside of specific corridors, connectivity between the transit city and its suburbs is complex, and the fixity of main transit lines creates challenges that are difficult to overcome.

- Mototrization: The last decades have experienced a growing level of motorization, as reflected by the production of automobiles, $80 \%$ of the world's automobiles are used in developed countries, but the share of developing countries is growing rapidly. A significant share of the growth of car production is attributed to the motorization of developing countries, especially in East and Southeast Asia. For example in 2003, more than 2 million cars were sold in China alone. For China and India to have a level of motorization similar to the average of industrial countries would involve a potential fleet of 640 and 513 million vehicles, respectively, whereas in 2004, the global vehicle fleet was estimated around 603 million. Considering the current level of technological development, this level of motorization is an energetic and a land consumption impossibility". 


\subsection{Environmental Effects}

Transportation is also considered as one of the main factors contributing to "Environmental Pollution-EP" with resulting "Global Warming-GW", which remains a challenge to be solved for all countries. Some estimate that $\mathrm{CO}_{2}$ emissions from Transportation constitute around $60 \%$ of total $\mathrm{CO}_{2}$ emissions including Industrial Activities and Energy Usage. Therefore, any solution that reduces the amount of Transportation required for reaching Goods and Services will also be a solution for EP and GW problems.

When considering health and fitness effects of transportation, we can consider air, noise, water, electromagnetic fields and hazardous material releases as the major categories. Our intention is not to analyze these effects in detail, but for example vehicle pollution emissions of carbon dioxide, carbon monoxide, durable chemicals, fine particulates, lead, methane, nitrogen oxides and nitrous oxide, ozone, road dust, sulfur oxides, volatile organic hydrocarbons and other toxics have human health effects, climate change effects and ecological damages. The emission of various solid, liquid and gas particles have different effects on the atmosphere, lithosphere, ecosphere and hydrosphere and have wide ranging implications in local, regional, and global dimensions. As an example, a study carried out by the Clean Air Act Corporation estimates per mile average vehicle emissions contributing to pollution as follows: volatile organic compounds-1 gr., nitrous oxides 2 gr., carbon monoxide 5 gr.

Furthermore, noise levels of $80 \mathrm{~dB}$ at a busy residential road, $90 \mathrm{~dB}$ inside a bus, $100 \mathrm{~dB}$ inside underground train, $110 \mathrm{~dB}$ near a busy airport and $120 \mathrm{~dB}$ for a loud car horn close-by are not good for human health since the threshold of pain for humans is $130 \mathrm{~dB}$. Noise zones of different transportation modes are $50-80 \mathrm{~dB}$ for road transportation, 55-85 dB for rail transportation and 60-110 dB for air transportation. Actually, the noise level by itself is a major stress-creating factor of transportation with negative implications on productive efficiency and general health. The effect of noise level can be categorized as:

- Physical effects: Hearing system etc.;

- Physiological effects: Increased blood pressure, heartbeat etc.;

- Psychological effect: Becoming irritable, uneasy, stressed;

- Performance effects: Negative effects on concentration, thinking, learning, productivity.

Furthermore, we can refer to the following information as analyzed in (Rodrigue et al., 2006), which looks at the environmental impacts of transportation:

\section{- “Atmosphere:}

Large scale diffusion of pollutants, high growth on a shot-term basis of the concentration of pollutants because of local conditions; Photochemical reactions caused by ultraviolet rays, notably over ozone, sulfur dioxide and nitrogen dioxide; Climatic changes (global warming); Acid rain; Synergetic and cumulative effects when pollutants are combined (e.g. smog and greenhouse gasses).

\section{- Hydrosphere:}

Diffusion of pollutants in a dissolved or colloidal state; Acidification and loss of neutralizing potential of ground and underground water; Drops of $\mathrm{pH}$ following snow melting (aquatic organism are particularly vulnerable); Growth in the solubility of several metals because of acidification; Additions of organic compounds, aluminum, manganese, calcium, magnesium and potassium by runoffs; Contamination of ground and underground water by nitrates; Modifications of hydrological systems by the construction and maintenance of infrastructure.

\section{- Lithosphere:}

Acid depositions; Liberation of toxic metallic ions (aluminum, cadmium, etc.) through acidification; Loss of nutrients, notably calcium and magnesium; Inhibition of the mineralization of nitrogen; Modifications in the compositions and the depth of decomposition gradient; Inhibition of decomposition; Loss of the soil flora and fauna; Fixation by plants of heavy metals (e.g. lead) and contamination; Removal and consumption of land; Extraction of raw materials like mineral products and energy.

\section{- Ecosphere:}

1) Aquatic ecosphere: Alteration of ecosystems in unforeseeable ways; Disappearance of vulnerable species and proliferation of tolerant ones; Reduction of bacterial treatment of organic matter by nitrification; Reduction of available nutrients to aquatic species; reproductive impediments.

2) Land ecosphere: Damages over the vegetation modifying: hydraulic cycles, the level of underground 
water resources, soil erosion, air purification capacity of ecosphere, food sources (agriculture) and entertainment and tourism potential; Reduction for the vital space; Reduction in the genetic potential of species; Reduction of the food supply and the alteration of the food chain; Consumption of resources.

3) Human ecosphere: Odors; Noise; Cardiovascular and respiratory problems; Susceptibility to infection; Drops in life expectancy; Injuries, incapacity, hospitalization, death; Damage to structures: loss of useful life, loss of property values (amortization), corrosion of metal structures (bronze, steel, etc.), destruction of historical and cultural monuments".

The following are some more information about environmental impacts of transportation (Rodrigue et al., 2006):

- "Petroleum Spills: The March 24, 1989 oil spill by the Exxon Valdez in the Prince William Sound (Alaska) released 260,000 barrels of oil and created a $6,700 \mathrm{~km}^{2}$ spill, of which $23 \%$ was removed. Total clean-up costs reached $\$ 1.2$ billion, around $\$ 400$ per barrel spilled. Significant drops in fisheries (up to $40 \%$ ) were observed in the following years.

- Automobile Emissions: Automobile emission factors depend on the characteristics of vehicles, driving characteristics and atmospheric conditions. For example, for driving characteristics, the optimal speed of a vehicle ranges around $60 \mathrm{~km}$. per hour, so a transportation system permitting optimal transport speeds and uninterrupted flows would provide minimal combustion levels and emission factors. Congestion, traffic signals and freeways have a high tendency to discriminate travel speeds, and thus raise combustion and emission levels".

\section{Conclusion}

Transportation Demand Management refers to policies recommended to reduce transportation. The idea in TDM is not to take transportation demand as a fixed quantity, but treat it as a variable quantity depending on the activity that transportation serves. Transportation is related with mobility in such a way that with the demand for education, there is a need for people to be mobile, creating a demand for transportation, motorization and energy (petroleum). With the mobility of people, however, there are also internal costs (users), external costs (society), and environmental impacts. On the other hand, IT use may be considered as an accessibility strategy. The basic idea is that if the same task can be achieved (accessibility) without people moving around so much (mobility with all its associated costs), it should be preferable to the others.

In this paper, we have attempted to make a detailed cost-benefit analysis of "IT at Home" as a substitute for "TT at Work" policy, first in a flexible education system-FES framework, and then in a more general work framework, where the same principles may apply. The analysis suggests that, the policy implementation may have positive effects on all of economic, social, organizational, land use and environmental dimensions. The only impeding factor appears to be the necessary structural change, with some production activities becoming obsolete.

The necessary condition for such a structural change may be the "Support of Governments", and "Increased Awareness and Sensitivity" of public about "Environmental Concerns" like "Global Warming-GW" and simply the "General Health Impacts" on all the present and future generation of people, animals and plants. Again, this policy may be implementable, only with another sufficiency condition that is required, which is a paradigm shift from a "Short-Term" perspective to "Long-Term" perspective, and only then efficiency in a "Pareto" sense PE may be achieved.

\section{References}

Button, K., Stouched, R., Bragg, M., \& Taylor, S. (2006). Telecommunications, Transportation and Location. Edward Elgar.

Fukuyama, F. (1996). Trust: The Social Virtues and the Creation of Prosperity. New York: Free Press.

Head, K. (2007). Elements of Multinational Strategy. Springer.

Rodrigue, J. P., Comtois, C., \& Slack, B. (2006). The Geography of Transport Systems. Routledge.

Seber, A. (2011b). Chicken-egg problem in education and organization theory. International Journal of Advanced Engineering Sciences and Technologies, 4(2), 10-13.

Seber, A. (2011c). An analytical exercise or a new approach to demand. International Journal of Advanced Engineering Sciences and Technologies, 4(2), 1-3.

Seber, A., \& Kaya, A. H. (2011a). Performance measures in education and productive efficiency. International Journal of Advanced Engineering Sciences and Technologies, 4(1), 22-25. 
Transportation Demand Management. (Online). TDM Encyclopedia. Victoria Transport Institute.

Wikipedia Encyclopedia. (Online). Transportation Economics.

\section{Copyrights}

Copyright for this article is retained by the author(s), with first publication rights granted to the journal.

This is an open-access article distributed under the terms and conditions of the Creative Commons Attribution license (http://creativecommons.org/licenses/by/3.0/). 